\title{
Neurokinin-1 Receptor Expression and Its Potential Effects on Tumor Growth in Human Pancreatic Cancer
}

\author{
Helmut Friess, Zhaowen Zhu, Veronique Liard, Xin Shi, Shailesh V. Shrikhande, \\ Li Wang, Klaus Lieb, Murray Korc, Carla Palma, Arthur Zimmermann, \\ Jean Claude Reubi, and Markus W. Büchler
}

Department of General Surgery (HF, XS, SVS, MWB), University of Heidelberg and Department of Psychiatry (KL), University of Freiburg, Medical School, Freiburg, Germany; Department of Visceral and Transplantation Surgery (HF, ZZ, VL, XS, SVS, LW, MWB), Institute of Pathology (AZ) and Division of Cell Biology and Experimental Cancer Research (JCR), Institute of Pathology, University of Bern, Inselspital, Switzerland; Departments of Medicine, Biological Chemistry, and Pharmacology (MK), University of California, Irvine, California; and Department of Pharmacology (CP) Menarini Research, Pomezia, Italy

SUMMARY: The neurokinin-1 receptor (NK-1R) and its ligand substance $\mathrm{P}(\mathrm{SP})$ are involved in the pathogenesis of certain neural tumors. Because nerves are significantly altered in pancreatic cancer, evidence for alteration of this pathway in human pancreatic cancer was sought. Expression of NK-1R was analyzed by real-time quantitative RT-PCR, in situ hybridization, immunohistochemistry, and Western blot analysis in normal human pancreatic and pancreatic cancer tissue samples and in pancreatic cancer cell lines. Furthermore, the influence of SP analogs and of the NK-1R antagonist MEN 11467 on pancreatic cancer cell growth was analyzed by sulforhodamine B (SRB) assay. By real-time quantitative RT-PCR, NK-1R mRNA was increased 36.7-fold $(p<$ 0.001 in human pancreatic cancer samples compared with normal controls. Enhanced NK-1R expression levels were not related to tumor grade but were associated with advanced tumor stage and poorer prognosis. By in situ hybridization and immunohistochemistry, NK-1R mRNA and immunoreactivity were only occasionally weakly present in acinar and ductal cells in the normal pancreas. In contrast, moderate to strong NK-1R mRNA signals and immunoreactivity were present in most cancer cells. By Western blot analysis, NK-1R was increased 26 -fold $(p<0.01)$ in pancreatic cancer samples in comparison to normal controls. NK-1R mRNA was detected in five pancreatic cancer cell lines by real-time quantitative RT-PCR, with the highest levels in CAPAN-1 cells and the lowest in ASPC-1 cells. SP analogs stimulated pancreatic cancer cell growth, depending on the NK-1R expression level, and this effect could be blocked by a selective NK-1R antagonist. These findings illustrate that the NK-1R pathway is activated in human pancreatic cancer and has the potential to contribute to cancer cell growth, thus suggesting the existence of a neuro-cancer cell interaction in vivo. (Lab Invest 2003, 83:731-742).

$D$ espite advances in understanding molecular mechanisms involved in the pathogenesis and progression of pancreatic cancer, this disorder is far from being completely understood (Kleeff et al, 2000). It remains the fourth or fifth leading cause of cancerrelated deaths in the Western world, with an overall 5 -year survival rate of $<5 \%$ (Faivre et al, 1998; Kuvshinoff and Bryer, 2000). Most patients with pancreatic cancer are discovered at an advanced stage when they are surgically unresectable. The knowledge of molecular alterations in pancreatic cancer has increased significantly in the last years with the identification of alterations in the K-ras (Porta et al, 1999; Yamaguchi et al, 2000), p16 (Caldas et al, 1994), p53 (Yamaguchi et al, 2000), Smad 4 (Hahn et al, 1996), and KAl1 (Friess et al, 1998; Guo et al, 1996) genes in

DOI: 10.1097/01.LAB.0000067499.57309.F6

Received October 2, 2002.

Address reprint requests to: Dr. H. Friess, Department of General Surgery, University of Heidelberg, D-69120 Heidelberg, Germany. E-mail: helmut_friess@med.uni-heidelberg.de a high percentage of tumors. Furthermore, enhanced expression of growth factors, growth factor receptors, and cytokines also has been identified in pancreatic cancer samples (Friess et al, 1999a).

Recent studies have demonstrated that neuropeptides and their receptors influence the development and progression of neuronal tumors (El-Salhy and Sandstrom, 1999) Three types of tachykinin receptors, namely neurokinin-1 receptor (NK-1R), neurokinin-2 receptor (NK-2R), and neurokinin-3 receptor (NK-3R) have been characterized and are preferentially activated by substance $P(S P)$, neurokinin $A$, and neurokinin B, respectively (Frossard and Advenier, 1991). $\mathrm{NK}-1 \mathrm{R}$ belongs to the class of seven transmembrane domain receptors that interact with intracellular effector systems via guanine nucleotide-binding regulatory proteins (G-proteins) (Quartara and Maggi, 1997). NK-1R is abundantly present in the rat pituitary and in AtT20 mouse pituitary tumor cells, giving a hint that this receptor might be involved in the pathogenesis of these tumors (Winkler et al, 1995). Furthermore, in human glioma cells, NK-1R stimulated by SP triggers a number of biologic responses that are potentially 
relevant for tumor growth and progression (Lieb et al, 1997, 1998; Palma et al, 1999b).

In contrast to the growth-promoting influences of $\mathrm{NK}-1 \mathrm{R}$, the inhibitory effects of its preferential ligand SP on invasion and migration are reported in prostate cancer cells (Nagakawa et al, 1998). Furthermore, SP reduces the invasive potential of murine Colon 26-L5 tumor cells in a concentration-dependent manner, and several SP analogs exhibit growth inhibitory effects on small cell lung cancer cells (Nyeki et al, 1998; Ogasawara et al, 1997).

By autoradiography, SP binding receptors (mainly NK-1R) are observed at a relatively high percentage in astrocytomas, glioblastomas, and breast cancer but at a much lower percentage in pancreatic cancer (1/9) and colonic cancer (1/21) (Hennig et al, 1995; Reubi et al, 1996). Based on these observations, it was postulated that NK-1R is involved in host-tumor interactions and may be crucial for tumor development and metastasis, thus implying that it may be used as a target for tumor therapy in human colorectal carcinomas (Nyeki et al, 1998; Ogasawara et al, 1997). In human hepatocellular carcinomas, because NK-1R was mainly localized in the intratumorous and peritumorous blood vessels, it was suggested that NK-1R might be involved in the regulation of tumor-associated blood flow (Reubi et al, 1999), thereby regulating tumor cell growth.

Because nerves and nerve growth-promoting factors are altered in pancreatic cancer and because a strong interaction between pancreatic cancer cells and nerves exist (Pour et al, 1991; Zhu et al, 1999), in the present study NK-1R mRNA expression in the normal pancreas, pancreatic cancer tissue samples, and pancreatic cancer cell lines was investigated. We report that NK-1R is up-regulated in human pancreatic cancer and that pancreatic cancer cell growth is stimulated by the neurotransmitter SP. These findings suggest a link between the neural system and pancreatic cancer cell growth and suggest the existence of neuro-cancer cell crosstalk.

\section{Results}

\section{Quantification of NK-1R mRNA Expression by Real-Time Quantitative RT-PCR}

Real-time quantitative RT-PCR was performed to analyze NK-1R mRNA expression (Fig. 1A) using 7S RNA (Fig. 1B) as internal control. A strong inverse linear relationship between the number of the cycle at the threshold and the log of the starting copy number was achieved for NK-1R $(r=0.971)$ and for $7 S(r=0.991)$.

The mean NK-1R/7S mRNA ratio was $0.07 \pm 0.02$ (mean \pm SEM) in the normal pancreatic tissue samples and $2.63 \pm 0.58$ (mean \pm SEM) in pancreatic cancer. Therefore the NK-1R mRNA level was approximately 36.7-fold higher in pancreatic cancer tissues when all pancreatic cancer samples were compared with the normal controls $(p<0.001$ ) (Fig. 2A). A value of 0.25 , which was the highest mRNA expression value in normal controls, was defined as the cutoff value.
Fourteen pancreatic cancer samples (28\%) ranged within this limit. Among the cancer tissues that exhibited increased NK-1R mRNA levels, 12 (24\%) pancreatic cancer samples had NK-1R mRNA levels between 0.25 and 1.00, 15 (30\%) pancreatic cancer samples had NK-1R mRNA levels between 1.00 and 5.00, and $9(18 \%)$ cancer samples had NK-1R mRNA levels higher than 5.00. In the pancreatic cancer cell lines, the NK-1R/7S mRNA ratio was $0.2 \pm 0.03$ in PANC-1, $0.17 \pm 0.02$ in MIA-PaCa-2, $0.52 \pm 0.08$ in CAPAN-1, $0.09 \pm 0.01$ in ASPC-1, and $0.09 \pm 0.02$ in T3M4 cells (Fig. 2B).

\section{Correlation of NK-1R mRNA Expression Levels with Clinicopathologic Parameters}

The expression levels of NK-1R mRNA determined by real-time quantitative $\mathrm{RT}$-PCR in pancreatic cancer samples were related to tumor stage and tumor grade. There was a significant difference in NK-1R mRNA expression levels with regard to the tumor stage (Fig. 2C) but not the tumor grade (Fig. 2D). The KruskalWallis test confirmed that early tumor stages had significantly lower NK-1R mRNA levels than advanced tumor stages ( $p<0.05$, Fig. $2 C$ ).

Furthermore, it was determined whether a relationship exists between the NK-1R mRNA levels and survival after resection. When survival probabilities in the four groups of patients with normal, low, moderate $(>0.25-5.00)$, and high (>5.00) NK-1R mRNA levels were compared, there was a significant difference between cancer patients with normal expression levels compared with patients with low and moderately increased NK-1R mRNA levels ( $p<0.05$, Fig. 3). Patients whose tumors exhibited low to moderately increased NK-1R mRNA levels lived significantly shorter lengths of time (median 11 months, lower quartile 8 months, upper quartile 15 months) compared with patients whose tumors had NK-1R mRNA expression levels comparable with the normal controls (median 17 months, lower quartile 11 months, upper quartile 48 months). Patients with highly increased NK-1R mRNA levels (>5.0) showed a tendency for better survival (not significant) than patients with low and moderate NK1-R mRNA expression levels (Fig. 3).

\section{Localization of NK-1R mRNA by In Situ Hybridization}

The localization of NK-1R mRNA in normal pancreas and in pancreatic cancer samples was determined by in situ hybridization. In the normal pancreas, NK-1R mRNA signals were weakly present only on occasion in acinar and ductal cells (Fig. 4A), blood vessels (Fig. 4A, inset left upper corner), fibroblast-like cells, nerves (Fig. 4A, inset left upper corner) and ganglia; signals were weakly to moderately present in islet cells (Fig. $4 \mathrm{~A}$, inset right lower corner) (Table 2). In pancreatic cancer tissue samples, NK-1R mRNA signals were present in most cancer cells in moderate to strong intensity (Fig. 4B, Table 2). Moderate to strong NK-1R mRNA signals were also localized in blood vessels 


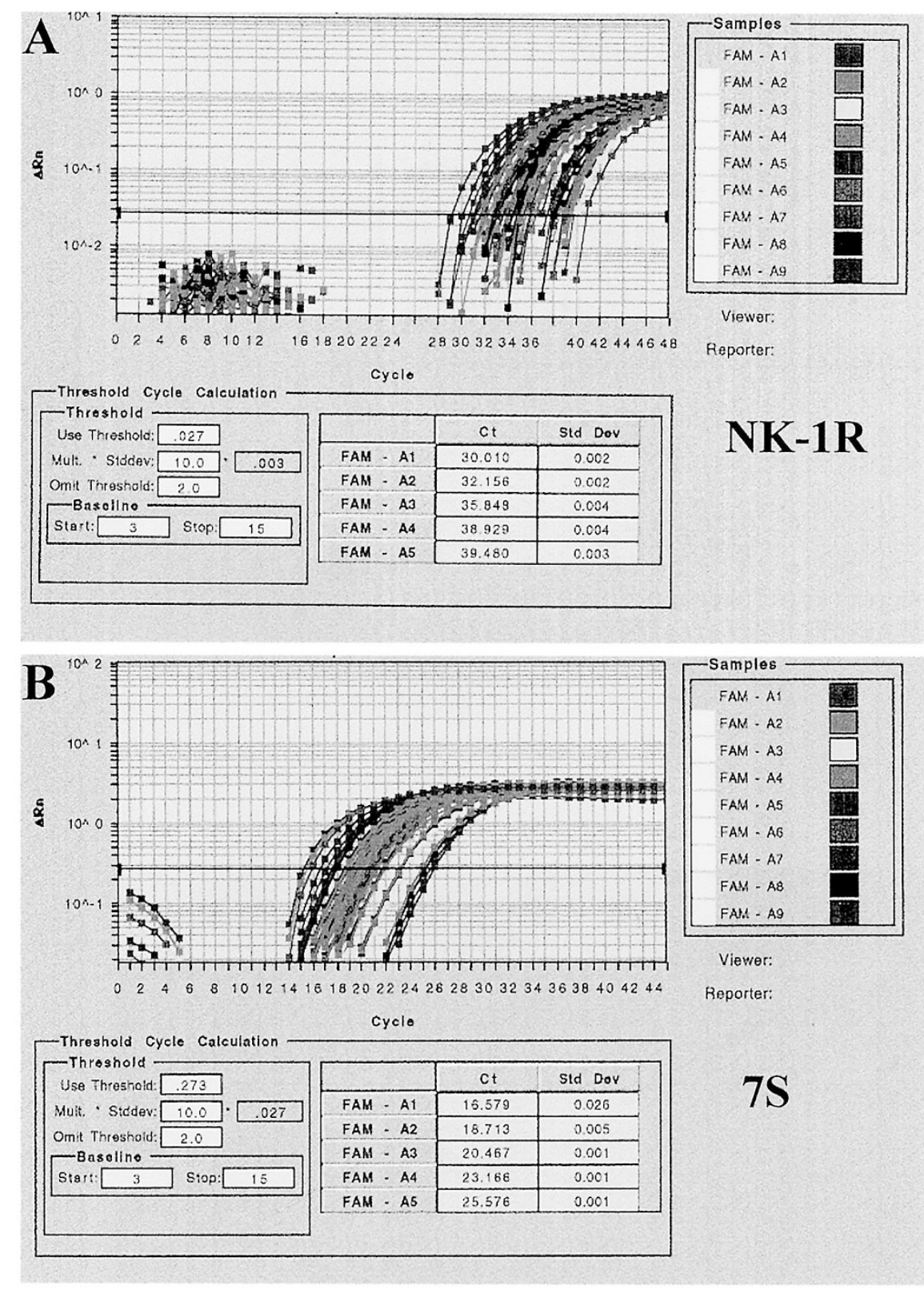

Figure 1.

Amplification plot obtained by real-time quantitative RT-PCR for neurokinin-1 receptor (NK-1R) mRNA (A) and 7S RNA (B). $\triangle$ Rn represents the normalized reporter signal minus the baseline signal established in the first 15 PCR cycles.

within the tumor mass (Fig. 4C, Table 3). Furthermore, nerves and ganglia also exhibited moderate to strong NK-1R mRNA signals (Fig. 4B, inset, and 4D, Table 2). Even some fibroblasts (Fig. 4B, arrowhead) and inflammatory cells (Fig. 4B, arrow) showed moderate to strong NK-1R mRNA signals (Table 2). However, these signals were heterogeneous, and some of these cells did not show NK-1R mRNA signals. Some normal ductal cells around the tumor mass also exhibited weak NK-1R mRNA signals as in the normal controls. The remaining islet cells showed moderate to strong NK-1R mRNA signals (Table 2). Consecutive tissue sections hybridized with the sense NK-1R cRNA probe failed to produce specific signals.

\section{Localization of NK-1R by Immunohistochemistry}

NK-1R immunoreactivity was present in a pattern similar to that observed by in situ hybridization. In the normal pancreas, weak NK-1R immunoreactivity was occasionally observed in acinar and ductal cells (Fig. $4 \mathrm{E}$ ) and in fibroblast-like cells, in blood vessels (Fig. $4 \mathrm{E}$, inset left upper corner), nerves (Fig. 4E, inset left upper corner), and ganglia (Table 2). Islet cells exhibited weak to moderate NK-1R immunoreactivity (Fig. $4 \mathrm{E}$, inset right lower corner, Table 2). In contrast, in pancreatic cancer tissue samples, moderate to strong NK-1R immunoreactivity was present in most cancer cells (Fig. 4F), in blood vessels (Fig. 4G), in nerves (Fig. 

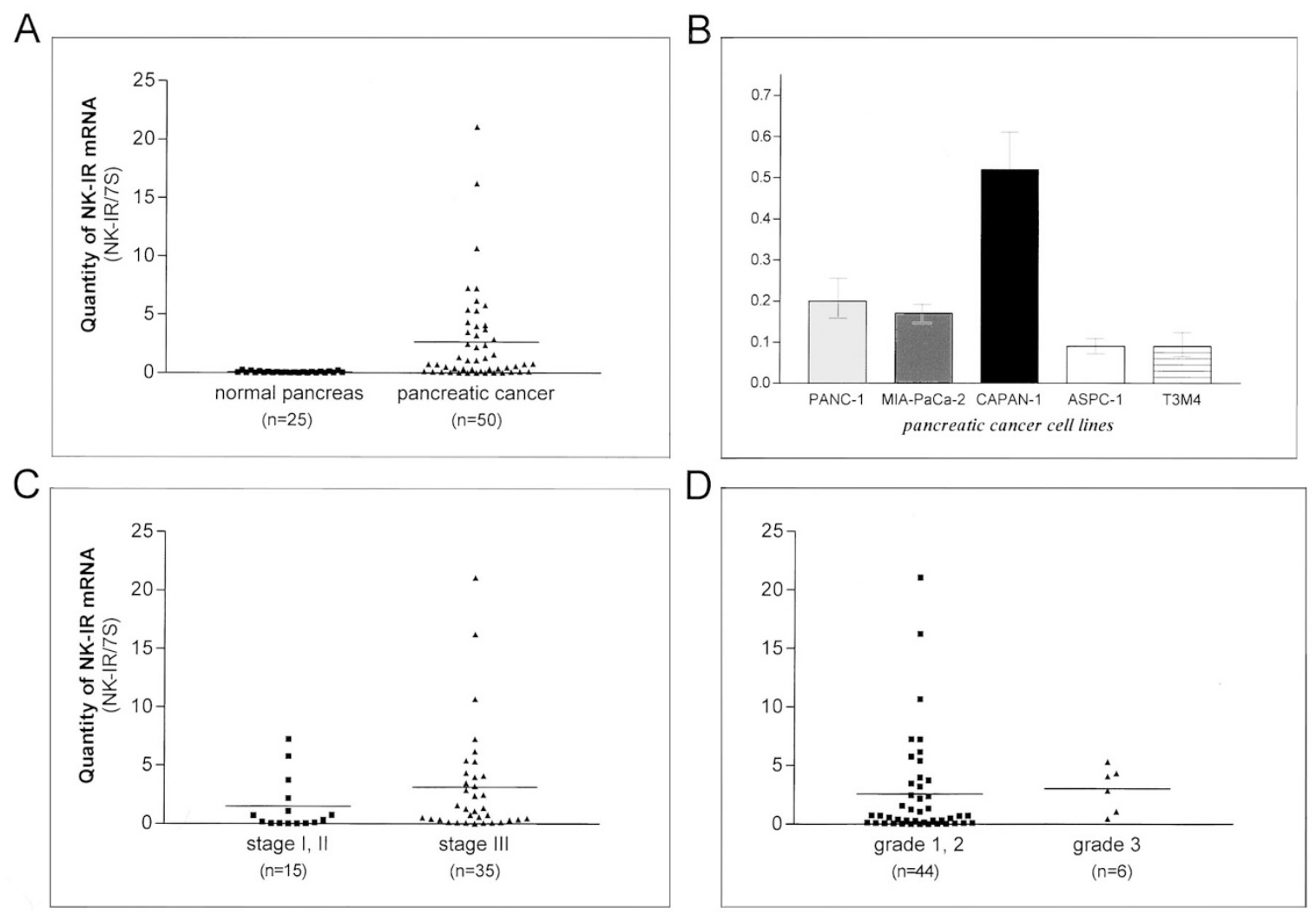

\section{Figure 2.}

A, Comparison of NK-1R mRNA levels. NK-1R mRNA levels were significantly higher $(p<0.001)$ in pancreatic cancer compared with normal controls. B, In the pancreatic cancer cell lines, CAPAN-1 cells exhibited the highest NK-1R mRNA levels. C, Stage III cancers exhibited significantly higher $(p<0.05)$ NK-1R mRNA levels than Stages I and II. D, No difference in NK-1R mRNA levels was found between grades 1/2 and grade 3 tumors.

$4 \mathrm{H}$ ), in ganglia (Fig. 4H, arrow), and in inflammatory cells and fibroblasts (Table 2). Strong NK-1R immunoreactivity was also observed in the remaining islet cells. The remaining normal acinar and ductal cells next to the tumor mass exhibited weak NK-1R immunoreactivity similar to that observed in normal controls (Table 2).

\section{Western Blot Analysis}

Western blot analysis was performed in four normal pancreas and four randomly selected pancreatic cancer tissues and in five pancreatic cancer cell lines. All of the normal and cancerous pancreatic tissue samples exhibited a single band of approximately $46 \mathrm{kDa}$ corresponding to the NK-1R protein (Fig. 5). Densitometric analysis of the Western blots demonstrated a 26-fold increase in NK-1R protein level in pancreatic cancer compared with the normal pancreas. In contrast to human tissues, NK-1R protein could not be detected by Western blot analysis in any of the pancreatic cancer cell lines (data not shown).

\section{Influence of SP Analogs and NK-1R Antagonist on Pancreatic Cancer Cell Proliferation}

According to the results of real-time quantitative RTPCR, CAPAN-1 cells exhibited the highest NK-1R
mRNA expression levels, whereas ASPC-1 cells exhibited the lowest NK-1R mRNA expression levels. Therefore, these two pancreatic cancer cell lines were chosen for further cell proliferation experiments.

Both SP analogs [(Sar9,Met(O2)11)-SP and (Nle 11)-SP] stimulated ASPC-1 (Fig. 6A) and CAPAN-1 (Fig. 6B) cell growth in a dose-dependent manner. However, growth stimulation was stronger in CAPAN-1 cells than in ASPC-1 cells. Although (Sar9,Met(O2)11)-SP exerted a stronger growth stimulation effect on CAPAN-1 and ASPC-1 cells than (Nle 11)-SP, this difference was not significant.

Because SP mediates its functions mainly via binding to NK-1R, the effect on cell proliferation of NK-1R blocking, via the specific NK-1R antagonist MEN 11467, was investigated. MEN 11467 exhibited an obvious growth inhibitory effect on both ASPC-1 and CAPAN-1 cells in a dose-dependent manner (Fig. 7A). Although the growth inhibitory effect of MEN 11467 was stronger in CAPAN-1 cells than in ASPC-1 cells, no significant difference was observed between the two pancreatic cancer cell lines.

The growth-stimulating effects of the two SP analogs at a dosage of $100 \mathrm{nM}$ on ASPC-1 (Fig. 7B) and CAPAN-1 cells (Fig. 7C) was reduced by MEN 11467 in a dose-dependent fashion. 


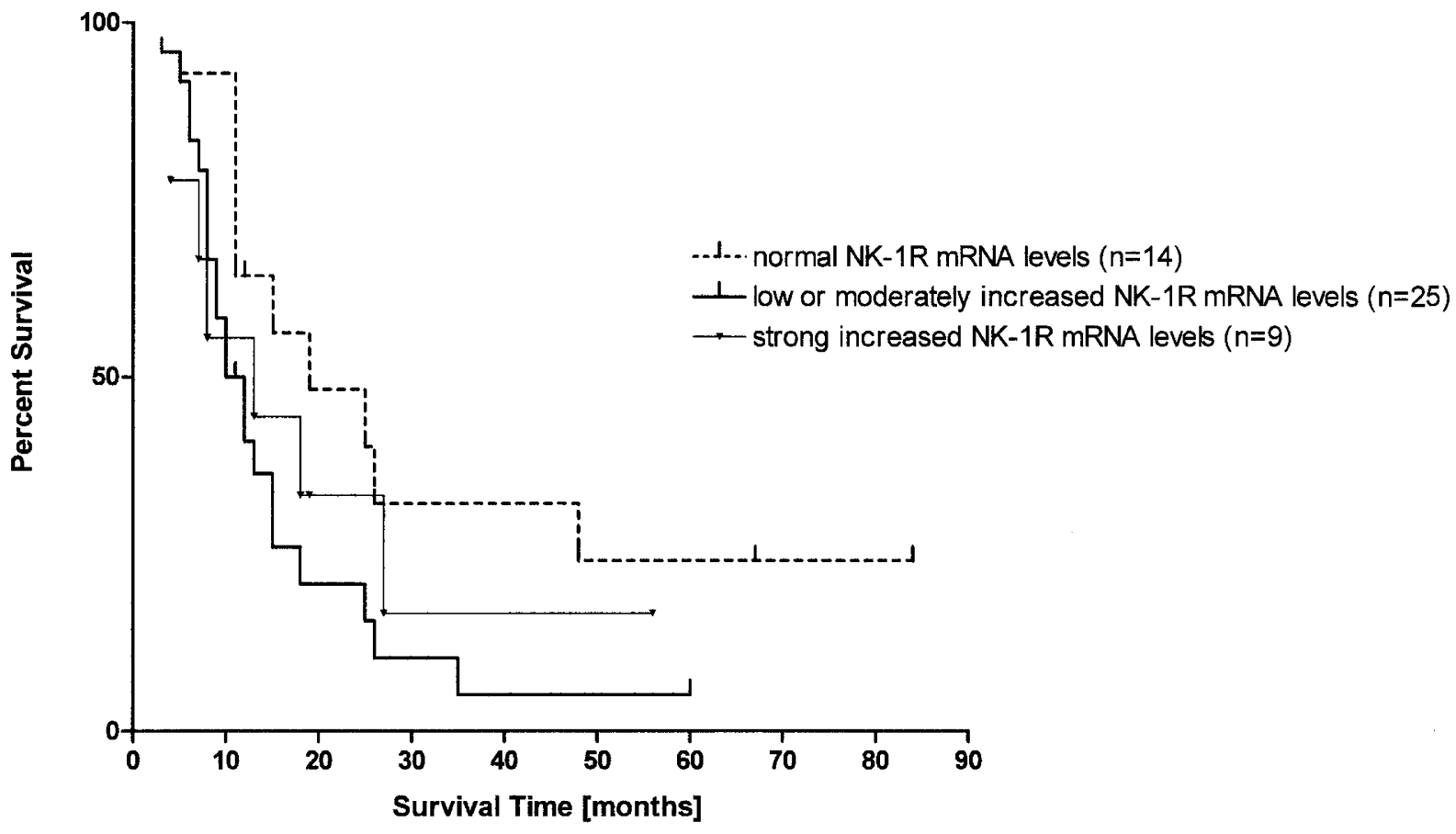

Figure 3.

Survival of pancreatic cancer patients in regard to the different NK-1R mRNA expression levels. Patients whose tumors exhibited low or moderate NK-1R mRNA expression levels lived significantly shorter $(p<0.05)$ compared with patients whose tumors exhibited NK-1R mRNA levels comparable to normal controls.

\section{Discussion}

In this study, the expression of NK-1R mRNA in human pancreatic cancer samples was investigated by real-time quantitative RT-PCR, in situ hybridization, immunohistochemistry, and Western blot analysis and compared with normal controls. In contrast to a previous study in which SP binding was observed in a low percentage of the cancer samples by receptor autoradiography (Hennig et al, 1995), real-time quantitative RT-PCR showed markedly increased NK-1R mRNA levels in $72 \%$ of cancer samples, which was confirmed by Western blot analysis. By in situ hybridization and immunohistochemistry, NK-1R was present and overexpressed predominantly in pancreatic cancer cells. In addition, real-time quantitative RT-PCR demonstrated NK-1R mRNA expression in five pancreatic cancer cell lines. Furthermore, pancreatic cancer cell growth could be stimulated by SP analogs. These findings indicate that the neurotransmitter SP can modulate the growth of pancreatic cancer cells and that there might exist a direct interaction between the neural system and pancreatic cancer cells.

The exact biologic function of NK-1R in carcinogenesis, especially in solid tumors, is not well understood. The limited data that have addressed the influence of neurotransmitters on cancer cell proliferation suggest that SP binding to its receptor can result in bifunctional activities that are dependent on the histologic type of the tumor. For instance, NK-1R stimulated by $\mathrm{SP}$ triggers a number of biologic responses in human glioma cells that are potentially relevant for tumor growth. It enhances the secretion of IL-6 and transforming growth factor $\beta 1$ and stimulates DNA synthe- sis and cell proliferation (Lieb et al, 1998; Palma et al, 1999b). On the other hand, inhibitory effects of SP have been reported in prostate cancer cells (Nagakawa et al, 1998), in murine Colon 26-L5 tumor cells (Ogasawara et al, 1997), in small cell lung cancer cells (Nyeki et al, 1998), and in human glioma U373 MG xenografts transplanted into nude mice (Palma et al, 2000). The reasons why SP exhibits stimulatory effects in one tumor type and inhibitory effects in another are not readily evident and do not seem to be solely dependent on the NK-1R receptor status. However, because a certain percentage of cancer samples do not express NK-1 receptors, it is plausible that SP binds to the other subtypes of the NK receptor family ("cross talk" mechanism) and these receptors in turn mediate inhibitory actions (Mussap et al, 1993).

Our study on cultured pancreatic cancer cells is the first reported one analyzing the influence of SP analogs on pancreatic cancer cell growth. It reveals that SP analogs stimulate pancreatic cancer cell proliferation in a dose-dependent manner and that the growthstimulating effects are positively related to the NK-1R mRNA expression level. Subsequently the simultaneous incubation of SP analogs with MEN 11467, a potent and selective NK-1R antagonist, abolished SP-mediated growth stimulation. The experimental data observed in cultured pancreatic cancer cells correlated well with the molecular findings in human pancreatic cancer samples. In human pancreatic cancer samples, the NK-1R mRNA levels were strongly increased. Tumor samples of patients with advanced tumor stages exhibited significantly higher NK-1R mRNA levels, suggesting that NK-1R possibly plays a 

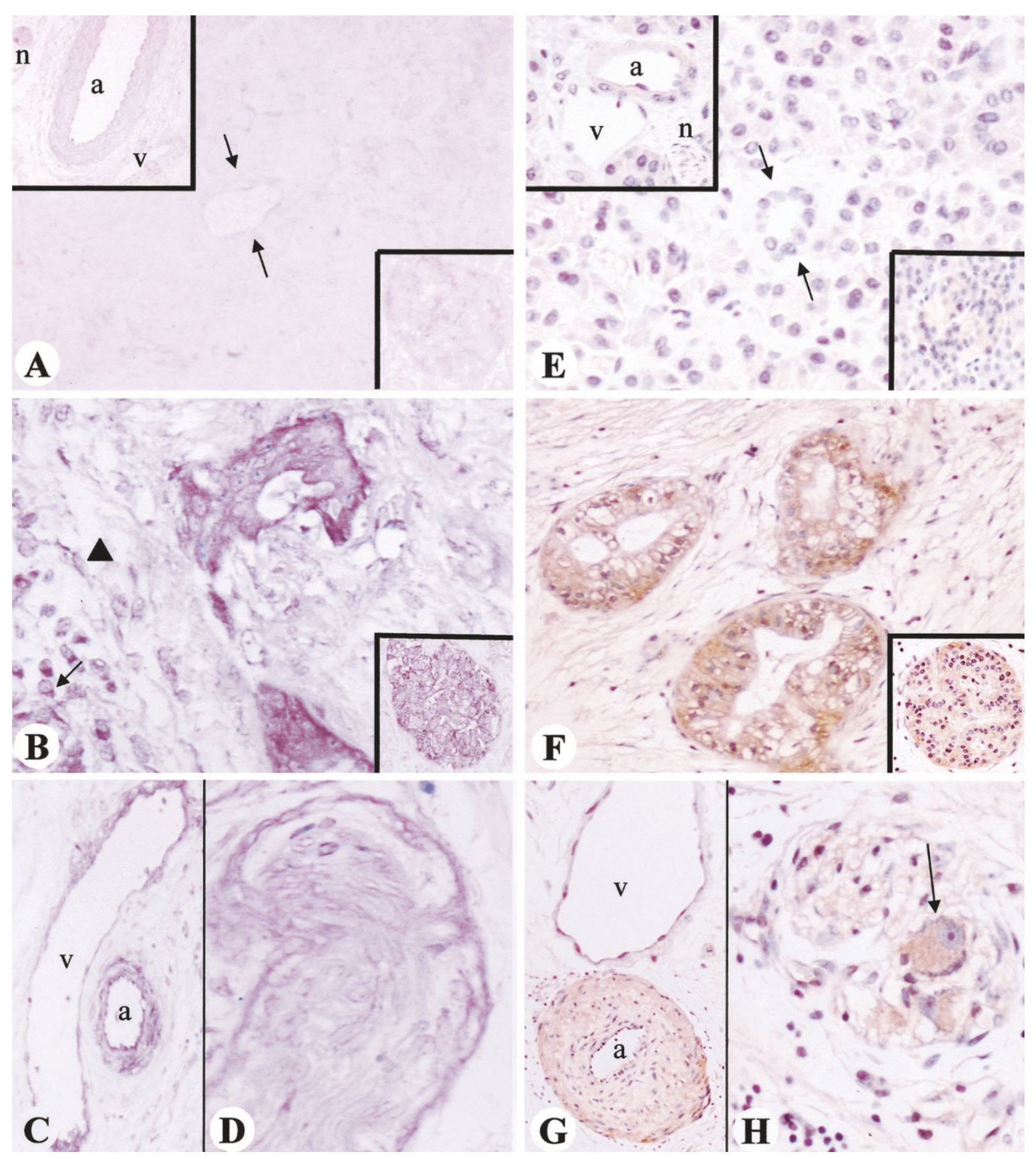

Figure 4.

In situ hybridization ( $A$ to $D$ ) and immunohistochemistry ( $E$ to $H$ ) of NK-1R in normal pancreas ( $A$ and $E$ ) and pancreatic cancer ( $B$ to $D$, F to $H)$. Normal acinar and ductal cells showed weak NK-1R mRNA signals ( $A$, arrow. duct) and immunoreactivity ( $E$, arrow. duct). The insets in the left upper corners of $A$ and $E$ show arteries $(a)$, veins $(v)$, and nerves $(n)$; the insets in the right lower corners show islets. Pancreatic cancer cells exhibited strong NK-1R mRNA signals (B) and NK-1R immunoreactivity (F). Also some fibroblasts (B, arrowhead) and inflammatory cells (B, arrow) showed moderate to strong NK-1R mRNA signals. The insets in B and $F$ show a nerve exhibiting moderate to strong NK-1R signals. Blood vessels ( $C$ and $G$ ), nerves, and ganglia ( $D$ and $H$ ) exhibited moderate to strong NK-1R mRNA signals. Original magnification: $A$ to $C$ and $E$ to $G, \times 200 ; D$ and $H, \times 400$.

role in the progression of human pancreatic cancer. However, no relationship between NK-1R expression and tumor differentiation was observed, indicating that NK-1R does not seem to influence pancreatic cancer cell differentiation. We also analyzed whether NK-1R expression levels influence the survival of pancreatic cancer patients. Interestingly, patients whose tumors exhibited low to moderate, but not strong, NK-1R mRNA overexpression survived significantly for a shorter duration compared with patients whose tumors showed no evidence of up-regulation of NK-1R mRNA. Therefore, up-regulation of NK-1R in pancreatic cancer seems to be of clinical significance. However, whether there exists a direct interaction 
Table 1. Primers and Probes used for TaqMan Real-Time Quantitative RT-PCR

\begin{tabular}{llc}
\hline Primer/probe & \multicolumn{1}{c}{ Sequence } & Size (bp) \\
\hline NK-1R & & \\
Forward primer & 5'-TCT CCA CTA ACA CCT CGG AAC C-3' & 22 \\
Reverse primer & 5'-CAG CTG CCC AAA GGA CAA TT-3' & 20 \\
Probe & 5'FAM-ATC AGT TCG TGC AAC CAG CCT GGC-3' TAMRA & 24 \\
7 S & & \\
Forward primer & 5'-ACC ACC AGG TTG CCT AAG GA-3' & 20 \\
Reverse primer & 5'-CAC GGG AGT TTT GAC CTG CT-3' & 20 \\
Probe & 5'FAM-TGA ACC GGC CCA GGT CGG AAA-3'TAMRA & 21 \\
\hline
\end{tabular}

Table 2. Localization and Semiquantitative Evaluation of NK-1R mRNA/Protein in Normal and Pancreatic Cancer Tissues

\begin{tabular}{lcc}
\hline Histologic structure & Normal pancreas & Pancreatic cancer \\
\hline Normal acinar cells & $+^{*}$ & $+^{*}$ \\
Normal ductal cells & $+^{*}$ & $+^{*}$ \\
Cancer cells & Not present & $++/+++$ \\
Inflammatory cells & Not present & $++/+++$ \\
Fibroblasts & $+^{*}$ & $++/+++$ \\
Arteries & $+^{*}$ & $++/+++$ \\
Veins & $+^{*}$ & $++/+++$ \\
Nerves & $+^{*}$ & $++/+++$ \\
Ganglia & $+^{*}$ & $++/+++$ \\
Islet & $+/++$ & $++/+++$ \\
\hline
\end{tabular}

+ , weak; ++ , moderate; +++ , strong; ${ }^{*}$, occasional.

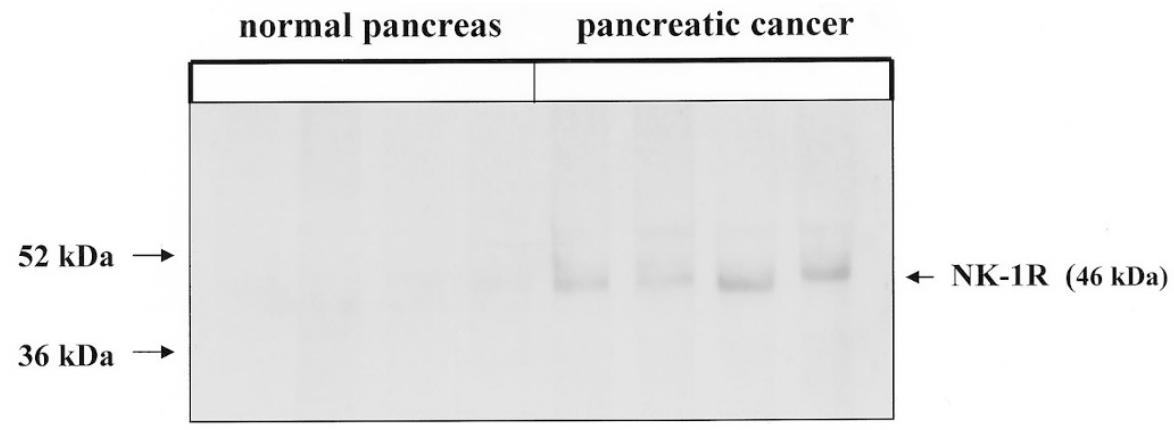

Figure 5 .

Western blot analysis of NK-1R in normal pancreas and pancreatic cancer tissue samples. NK-1R protein levels were markedly increased in pancreatic cancer compared with the normal controls.

between pancreatic cancer cells and the neuronal system still needs elucidation in further studies. Recently, up-regulation of NK-1R mRNA expression has been reported in chronic pancreatitis (Shrikhande et al, 2001). NK-1R mRNA was expressed mainly in nerves and ganglia, and there was a strong relationship to the pain syndrome in these patients. These observations in chronic pancreatitis support the existence of neuroimmune interactions that seem to exist also in pancreatic cancer and might influence cancer cell behavior (Büchler et al, 1992; DiSebastiano et al, 1997; Roggo et al, 2002).

In addition to expression of NK-1R in the pancreatic cancer cells, in situ hybridization and immunohistochemistry revealed that NK-1Rs were also present in blood vessels. This observation is consistent with previous studies in which up-regulation of SP-binding receptors as well as somatostatin receptors was reported in blood vessels of human colorectal cancers by autoradiography (Hennig et al, 1995; Reubi et al, 1994, 1996). When examined by receptor autoradiography, SP binding in pancreatic cancer cells is limited to a lower number of tumors; however, SP binding is quite obviously detectable in blood vessels not only within the tumor mass but also in the peritumorous tissue (Hennig et al, 1995). Similar findings were made in hepatocellular carcinomas (Reubi et al, 1999), suggesting that NK-1R might play a role in the host-tumor interaction and that vascular regulatory mechanisms in the tumor bed may be important for tumor development and could be used as potential targets in tumor therapy. Furthermore NK-1R can enhance vas- 

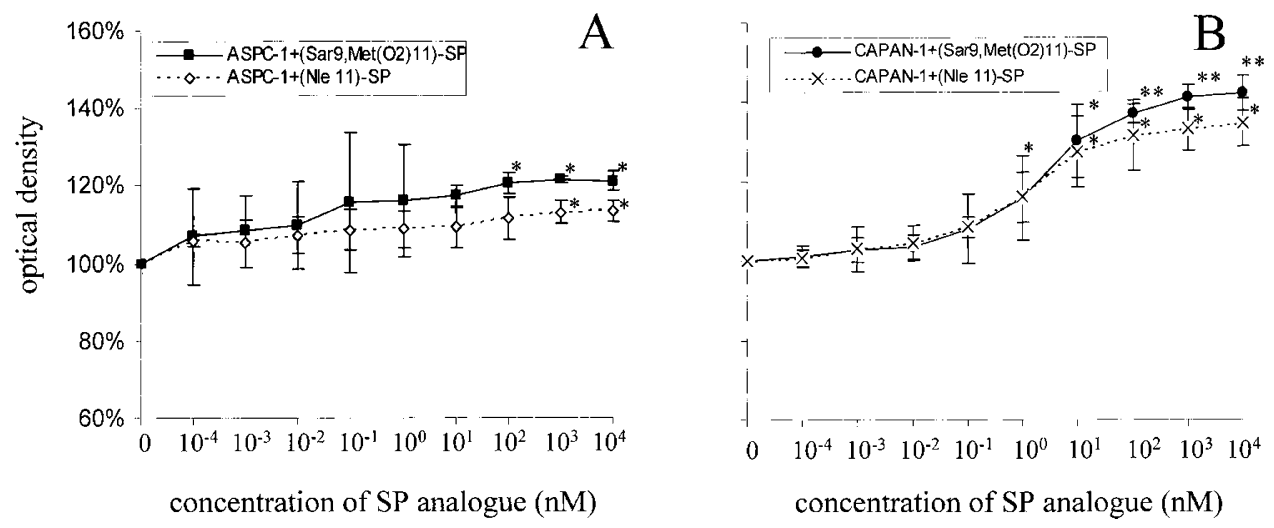

Figure 6.

Effects of two substance P analogs [(Sar9, Met(02)11)-SP and (Nle 11)-SP] on pancreatic cancer cell proliferation in ASPC-1 (A) and CAPAN-1 (B) cells. Data are expressed as percent change from unstimulated controls and are means \pm SEM of triplicate determinations for each cell line. ${ }^{*} p<0.05,{ }^{* *} p<0.01$.

cular permeability (Appelgren et al, 1998; Holzer, 1998; Reubi et al, 1994; Scott et al, 1994; Walsh et al, 1993), thereby influencing the migration of lymphocytes, granulocytes, and monocytes from blood to the tumor and peritumorous areas. Via these mechanisms, NK-1R on blood vessels can influence immune response, the migration of immune cells toward the tumor, and tumor growth and cancer cell migration (Hennig et al, 1995; Reubi et al, 1996).

These findings strongly suggest that the SP/NK-1R pathway might not only directly coregulate tumor growth but could also be indirectly involved in tumor regulation through vascular mechanisms. Therefore we suggest that nerves and neurotransmitters have the capacity to enhance pancreatic cancer growth through direct mitogenic effects via NK-1R on the cancer cells and through indirect effects that promote tumor angiogenesis.

\section{Materials and Methods}

\section{Patients and Tissue Sampling}

Pancreatic cancer tissues were obtained from 50 patients (27 men and 23 women) undergoing pancreatoduodenectomy (Whipple operation). The median age was 66 (range, 44-82) years. Tumor stage and histopathologic grading were recorded according to the classification of the International Union Against Cancer (Sobin and Wittekind, 1997). There were 7 Stage I, 8 Stage II, and 35 Stage III tumors. There were 9 patients with grade 1, 35 with grade 2, and 6 with grade 3 tumors. All except two patients, who died in the early postoperative period, were followed-up after the operation.

Normal human pancreatic tissues were obtained from 20 patients (12 men and 8 women) who were free of pancreatic disease. Sixteen samples were obtained through an organ donor program in which no candidates for pancreatic transplantation were present, and in four cases normal pancreas was taken from patients undergoing pancreatic resection. Histopathologically there were no differences between the organ donor pancreas and the resected normal pancreas samples.
The median age in the control group was 46 (range, 17-69) years.

Freshly removed tissue samples were immediately frozen in liquid nitrogen and stored at $-80^{\circ} \mathrm{C}$ until use for RNA and protein extraction and subsequently for real-time quantitative RT-PCR and Western blot analysis. Pancreatic tissues were also immediately fixed in paraformaldehyde solution and embedded in paraffin for in situ hybridization and immunohistochemistry. All studies were approved by the human subjects committee of the University of Bern, Switzerland.

\section{Pancreatic Cancer Cell Lines and Cell Culture}

Five human pancreatic cancer cell lines (PANC-1, MIA-PaCa-2, ASPC-1, CAPAN-1, and T3M4) that were used in this study were cultured in DMEM (PANC-1 and MIA-PaCa-2) or RPMI-1640 (ASPC-1, CAPAN-1, and T3M4) supplemented with $10 \%$ fetal bovine serum, $100 \mathrm{U} / \mathrm{ml}$ penicillin, and $100 \mu \mathrm{g} / \mathrm{ml}$ streptomycin.

\section{Real-Time Quantitative RT-PCR}

Real-time quantitative RT-PCR was performed as described previously with certain modifications (Conejo et al, 2000; Shrikhande et al, 2001) Briefly, after DNase treatment, total RNA was reverse transcribed into cDNA using random hexamers according to the manufacturer's instructions (Roche Diagnostics, Rotkreuz, Switzerland). The real-time quantitative RT-PCR analysis was performed with an automated sequence detection system (Prism 7700 Sequence Detector; PE Applied Biosystems, Weiterstadt, Germany) combined with a dual-label fluorogenic detection system (TaqMan) based upon the 5' nuclease assay. The 7S RNA gene was used as endogenous control. The sequences of primers and the probes for NK-1R and human $7 \mathrm{~S}$ are shown in Table 1.

All amplification reactions were performed in a final volume of $25 \mu \mathrm{l}$ containing $12.5 \mu \mathrm{l}$ of the TaqMan PCR Core Reagent kit (PE Applied Biosystems) and 25 ng of cDNA. Concentrations of primers and probes were optimized as follows: $200 \mathrm{~nm}$ for NK-1R forward 


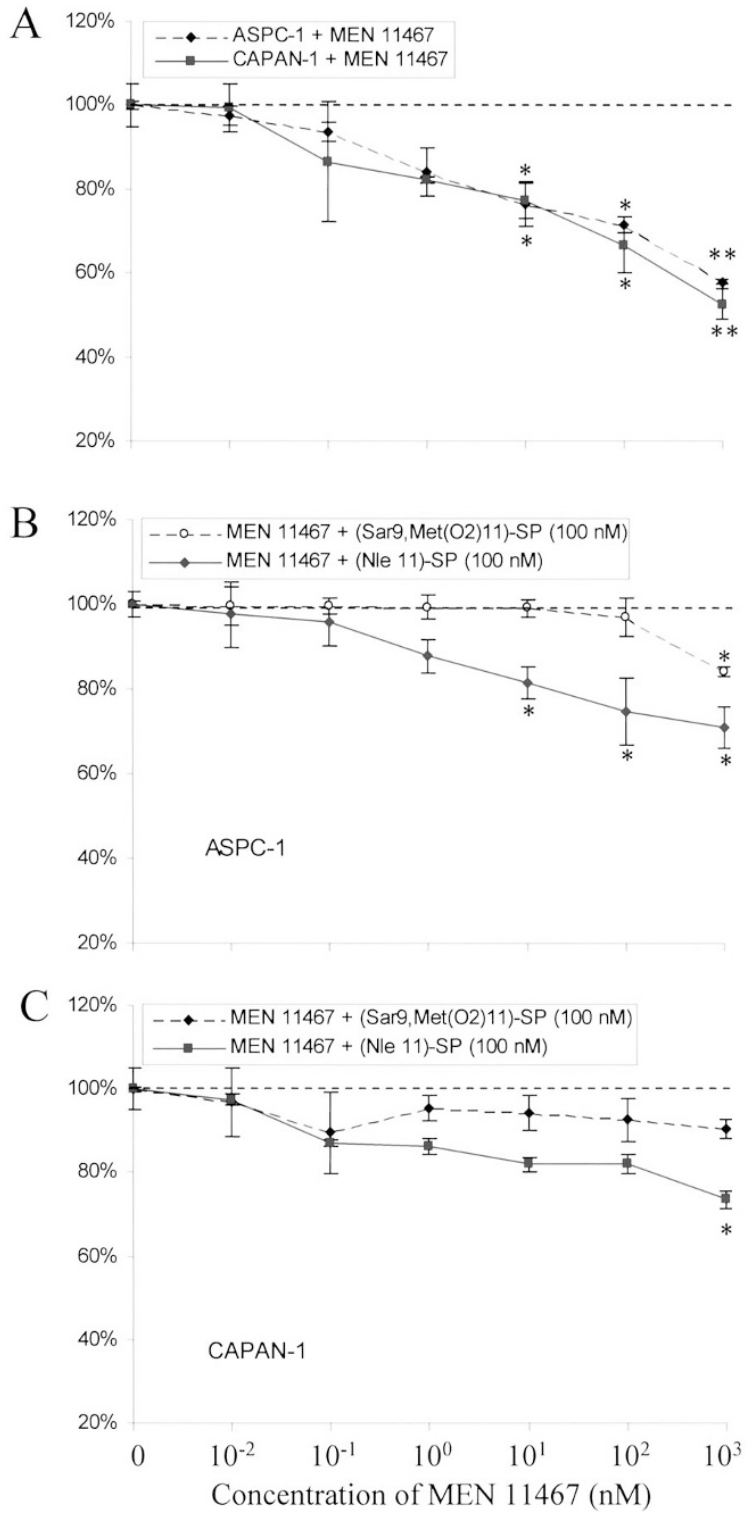

Figure 7.

Effects of MEN 11467 alone (A) or in combination with two SP analogs [(Sar9, $\operatorname{Met}(02) 11)-S P$ and (Nle 11)-SP] on cell proliferation in ASPC-1 (B) and CAPAN-1 (C) cells. Data are expressed as percent change from SP analogstimulated controls and are means \pm SEM of triplicate determinations for each cell line. ${ }^{*} p<0.05,{ }^{* *} p<0.01$.

primer, reverse primer, and NK-1R probe (FAM/ TAMRA); 300 nM for 7S forward primer, reverse primer, and $7 \mathrm{~S}$ probe (FAM/TAMRA). Thermal cycling was initiated with a 2-minute incubation at $50^{\circ} \mathrm{C}$ for the uracil $\mathrm{N}$-glycosylase reaction, followed by a 10-minute reaction at $95^{\circ} \mathrm{C}$ to activate the AmpliTaq Gold, and 48 PCR cycles for NK-1R and 45 PCR cycles for $7 S$ at $95^{\circ} \mathrm{C}$ for 15 seconds and $60^{\circ} \mathrm{C}$ for 1 minute, respectively (Fig. 1, A and B).

Data were analyzed using the relative standard curve method as reported previously (Conejo et al, 2000). Experiments were performed in duplicate for each data point. Each PCR run included five standard samples, one no-template control, and the experimental samples. Standard curves for both NK-1R and 7S were generated using cDNAs diluted serially (1:10) from one pancreatic cancer sample cDNA. The threshold was set at 10 standard deviations above the mean of the baseline fluorescence emission calculated from cycles 3 to 15. For each experimental sample, the relative amounts (copy number) of NK-1R mRNA and 7S RNA were determined from the standard curve. The normalized amount of NK-1R was determined by dividing the amount of NK-1R mRNA by the amount of 7S RNA for each sample. For pancreatic cancer cell lines, NK-1R mRNA analysis was repeated four times in duplicates.

\section{In Situ Hybridization}

To localize the site of NK-1R mRNA expression, in situ hybridization was performed as reported previously (Conejo et al, 2000; Shrikhande et al, 2001; Zhu et al, 2000b) Briefly, tissue sections were deparaffinized, rehydrated, and incubated in $0.2 \mathrm{M} \mathrm{HCl}$ for 20 minutes. After washing with $2 \times \mathrm{SSC}$, the tissues were digested with proteinase $\mathrm{K}(30 \mu \mathrm{g} / \mathrm{ml})$, fixed with $4 \%$ paraformaldehyde, washed, prehybridized, and hybridized. The prehybridization was performed for 2 hours at $50^{\circ} \mathrm{C}$. Hybridization was accomplished overnight at $50^{\circ} \mathrm{C}$. After hybridization, unbound cRNA probe was removed by washing in $2 \times \mathrm{SSC}$ and further by RNase treatment with $500,000 \mathrm{U} / \mathrm{ml}$ RNase T1 and $0.2 \mu \mathrm{g} / \mathrm{ml}$ DNase-free RNase. The slides were then incubated with an anti-DIG antibody conjugated with alkaline phosphatase (Roche Diagnostics). 5-bromo-4-chloro3-indolyl phosphate and nitroblue tetrazolium (Sigma, Buchs, Switzerland) were used for the color reaction.

Consecutive slides were incubated with the NK-1R sense probe as a negative control. Hybridization with the sense probe or pretreatment of the slides with RNase failed to produce specific in situ hybridization signals.

\section{Preparation of NK-1R Probe for In Situ Hybridization}

A 259-bp fragment of the human NK1 receptor cDNA (GenBank Accession Number: S62045) was generated by RT-PCR and subcloned into the pGEM-T Easy vector (Promega Biotechnology, Madison, Wisconsin) carrying promotors for the DNA-dependent SP6 and T7 RNA polymerases (Shrikhande et al, 2001). The authenticity of the subcloned cDNA fragments was confirmed by sequencing, using the dye terminator method (ABI 373A; Perkin Elmer, Rotkreuz, Switzerland). Sense and antisense NK-1R cRNA probes were prepared by DIG labeling after linearizing the plasmid using the Ribomax system (Promega Biotechnology).

\section{Immunohistochemistry}

Three- to 5- $\mu \mathrm{m}$ thick consecutive tissue sections were subjected to immunostaining using the streptavidin peroxidase technique (Friess et al, 1999b; Zhu et al, 2000a). After deparaffinization and rehydration, sections were submerged in Tris-buffered saline (TBS) solution (10 mm Tris-HCL, $0.85 \% \mathrm{NaCl}, \mathrm{pH} 7.4)$ containing $0.1 \%$ (vol/vol) Triton $\mathrm{X}-100$ for 15 minutes and 
then washed for 5 minutes in TBS. Endogenous peroxidase activity was quenched with $2 \%$ hydrogen peroxide in methanol for 20 minutes. Nonspecific binding sites were blocked by incubation with $10 \%$ normal rabbit serum for 30 minutes. Then the sections were incubated with a polyclonal goat anti-human NK-1R antibody (Santa Cruz Biotechnology, Santa Cruz, California) (1:500 dilution) at $4^{\circ} \mathrm{C}$ overnight. Bound antibody was detected with a biotinylated rabbit anti-goat IgG followed by a streptavidinperoxidase complex (Kirkegaard \& Perry Laboratories, Inc., Gaithersburg, Maryland). The color reaction was performed by incubation with diaminobenzidine tetrahydrochloride $(0.05 \%)$ as the substrate. Finally the sections were counterstained with Mayer's hematoxylin and mounted. To ensure specificity of the primary antibodies, consecutive tissue sections were incubated either in the absence of the primary antibody or with a nonimmunized goat IgG antibody. In these sections, no specific immunostaining was detected.

\section{Western Blot Analysis}

Western blot analysis was performed as previously reported with certain modifications (Wang et al, 2000). Briefly, $200 \mathrm{mg}$ of tissue was powdered in liquid nitrogen and then homogenized in lysis buffer $(50 \mathrm{~mm}$ Tris- $\mathrm{HCl}, \mathrm{pH}$ 7.5; 150 mm NaCl; 2 mм EDTA; 1\% SDS) supplemented with a protease inhibitor cocktail (Roche Diagnostics). In case of pancreatic cancer cell lines, 3 to $5 \times 10^{6}$ cells were used for protein extraction. Cells were washed twice with ice-cold $1 \times$ PBS ( $\mathrm{pH} 7.4)$, collected, and homogenized in lysis buffer. The lysates were collected and centrifuged at $4^{\circ} \mathrm{C}$ for 30 minutes at $14,000 \mathrm{rpm}$ to remove the insoluble material. Protein concentration was measured by spectrophotometry using the BCA protein assay (Pierce, Rockford, Illinois). From each sample, $40 \mu \mathrm{g}$ of protein was separated on $12 \%$ SDS-polyacrylamide gels and electroblotted onto nitrocellulose membranes.

Blots were incubated in blocking solution (5\% nonfat milk in $20 \mathrm{~mm}$ Tris- $\mathrm{HCl}, 150 \mathrm{~mm} \mathrm{NaCl}, 0.1 \%$ Tween-20 [TBS-T]), followed by incubation with the polyclonal goat anti-human NK-1R antibody (Santa Cruz Biotechnology; 1:1000 dilution) for 1 hour at room temperature. The membranes were then washed with TBS-T and incubated with a horseradish peroxidase-conjugated donkey anti-goat IgG (1:3000 dilution) antibody for 30 minutes at room temperature. Antibody detection was performed with an enhanced chemiluminescence reaction (ECL Western blotting detection; Amersham Life Science, Amersham, United Kingdom).

\section{Determination of Cell Proliferation by SRB Assay}

The influence of SP on pancreatic cancer cell proliferation was determined by the sulforhodamine B (SRB) assay. Two SP analogs, (Sar9,Met(O2)11)-SP and (Nle 11)-SP, were used (Bachem, Bubendorf, Switzerland). In addition, the effects of a highly selective and specific human NK-1R antagonist MEN 11467 (Menarini Ricerche, Promezia, Italy) was also tested. The chemical characteristics and biologic activity of MEN 11467 have been described previously (Fisher et al, 1997; Fournier et al, 1982; Palma et al, 1999a, 1999b). The SRB assay was conducted in 96-well plates as described before (Zhu et al, 2000b). Cells were plated at a density of 3000 cells per well and incubated overnight. Plates were then washed with $1 \times \mathrm{PBS}, \mathrm{pH}$ 7.4 , and serum-free medium was added with different concentrations of the SP analogs $\left(0,10^{-2}, 10^{-1}, 10^{\circ}\right.$, $\left.10^{1}, 10^{2}, 10^{3}, 10^{4} \mathrm{~nm}\right)$, MEN $11467\left(0,10^{-4}, 10^{-3}\right.$, $\left.10^{-2}, 10^{-1}, 10^{0}, 10^{1}, 10^{2}, 10^{3}\right)$, and the SP analogs $\left(10^{2}, 10^{3}, 10^{4} \mathrm{~nm}\right.$, respectively) plus MEN 11467 (0, $\left.10^{-2}, 10^{-1}, 10^{0}, 10^{1}, 10^{2}, 10^{3} \mathrm{~nm}\right)$. The cells were continuously incubated for 48 hours. Cells were fixed with $10 \%$ trichloric acid for 1 hour at $4^{\circ} \mathrm{C}$ and stained with $0.4 \%$ SRB (Sigma, St. Louis, Missouri) for 15 minutes at room temperature followed by washing with $1 \%$ glacial acetic acid to remove the unstained SRB. Stained cells were dried and dissolved in $10 \mathrm{~mm}$ Tris- $\mathrm{HCl}$, and the optical density of cells was measured in a microplate reader at $540 \mathrm{~nm}$. All experiments were performed in triplicate and repeated three times.

\section{Statistical Analysis}

Data are expressed as median and range or as mean $\pm \mathrm{SD}$ or mean \pm SEM. For statistical comparison, the Mann-Whitney test, the Student's $t$ test, and the Kruskal Wallis test were used. Survival curves were calculated using the Kaplan-Meier method and compared by the trend log-rank test (Swinscow, 1988). The Statistical Package for Social Sciences (SPSS, Inc., Chicago, Illinois) was used for statistical analysis. A $p$ value $<0.05$ was considered significant.

\section{Acknowledgement}

The authors thank Dr. M. Martignoni for his help in the statistical data analysis and for preparation of the figures.

\section{References}

Appelgren A, Appelgren B, Kopp S, Lundeberg T, and Theodorsson E (1998). Substance P-associated increase of intra-articular temperature and pain threshold in the arthritic TMJ. J Orofac Pain 12:101-107.

Büchler MW, Weihe E, Friess H, Malfertheiner $\mathrm{P}$, Bockmann E, Müller S, Nohr D, and Beger HG (1992). Changes in peptidergic innervation in chronic pancreatitis. Pancreas 7:183-192.

Caldas C, Hahn SA, daCosta LT, Redston MS, Schutte M, Seymour AB, Weinstein CL, Hruban RH, Yeo CJ, and Kern S (1994). Frequent somatic mutations and homozygous deletions of the p16 (MTS1) gene in pancreatic adenocarcinoma. Nat Genet 8:27-32.

Conejo JR, Kleeff J, Koliopanos A, Matsuda K, Zhu ZW, Goecke H, Bicheng N, Zimmermann A, Korc M, Friess H, and Büchler MW (2000). Syndecan-1 expression is up-regulated in pancreatic but not in other gastrointestinal cancers. Int $\mathrm{J}$ Cancer 88:12-20. 
DiSebastiano P, Fink T, Weihe E, Friess H, Innocenti P, Beger HG, and Büchler MW (1997). Immune cell infiltration and growth-associated protein 43 expression correlate with pain in chronic pancreatitis. Gastroenterology 112:1648-1655.

El-Salhy M and Sandstrom O (1999). How age changes the content of neuroendocrine peptides in the murine gastrointestinal tract. Gerontology 1:17-22.

Faivre J, Forman D, Esteve J, Obradovic M, and Sant M (1998). Survival of patients with primary liver cancer, pancreatic cancer and biliary tract cancer in Europe. Eur J Cancer 14:2184-2190.

Fisher L and Pennefather JN (1997). Potencies of agonists acting at tachykinin receptors in the oestrogen-primed rat uterus: effects of peptidase inhibitors. Eur $\mathrm{J}$ Pharmacol 335:221-226.

Fournier A, Couture R, Regoli D, Gendreau M, and St-Pierre $S$ (1982). Synthesis of peptides by the solid-phase method. 7 . Substance P and analogues. J Med Chem 25:64-68.

Friess H, Guo XZ, Graber HU, Zimmermann A, Korc M, and Büchler MW (1998). Reduced KAl1 expression in pancreatic cancer is associated with lymph node and distant metastases. Int J Cancer 79:349-355.

Friess H, Guo XZ, Nan BC, Kleeff J, and Büchler MW (1999a). Growth factors and cytokines in pancreatic carcinogenesis. Ann NY Acad Sci 880:110-121.

Friess H, Wang L, Zhu Z, Gerber R, Schroder M, Fukuda A, Zimmermann A, Korc M, and Büchler MW (1999b). Growth factor receptors are differentially expressed in cancers of the papilla of vater and pancreas. Ann Surg 6:767-774.

Frossard N and Advenier C (1991). Tachykinin receptors and the airways. Life Sci 26:1941-1953.

Guo X, Friess H, Graber HU, Kashiwagi M, Zimmermann A, Korc M, and Büchler MW (1996). KAl1 expression is upregulated in early pancreatic cancer and decreased in the presence of metastases. Cancer Res 21:4876-4880.

Hahn SA, Schutte M, Hoque AT, Moskaluk CA, da Costa LT, Rozenblum E, Weinstein CL, Fischer A, Yeo CJ, Hruban RH, and Kern SE (1996). DPC4, a candidate tumor suppressor gene at human chromosome 18q21.1. Science 271:350-353.

Hennig IM, Laissue JA, Horisberger U, and Reubi JC (1995). Substance-P receptors in human primary neoplasms: Tumoral and vascular localization. Int J Cancer 6:786-792.

Holzer P (1998). Implications of tachykinins and calcitonin gene-related peptide in inflammatory bowel disease. Digestion 59:269-283.

Kleeff J, Friess H, Berberat PO, Martignoni ME, Z'graggen K, and Büchler MW (2000). Pancreatic cancer: New aspects of molecular biology research. Swiss Surg 5:231-234.

Kuvshinoff BW and Bryer MP (2000). Treatment of resectable and locally advanced pancreatic cancer. Cancer Control 5:428-436.

Lieb K, Fiebich BL, Berger M, Bauer J, and Schulze-Osthoff $K$ (1997). The neuropeptide substance $P$ activates transcription factor NF-kappa B and kappa B-dependent gene expression in human astrocytoma cells. J Immunol 159:49524958.

Lieb K, Schaller H, Bauer J, Berger M, Schulze-Osthoff K, and Fiebich $B L$ (1998). Substance $P$ and histamine induce interleukin- 6 expression in human astrocytoma cells by a mechanism involving protein kinase $\mathrm{C}$ and nuclear factorIL-6. J Neurochem 70:1577-1583.

Mussap CJ, Geraghty DP, and Burcher E (1993). Tachykinin receptors: A radioligand binding perspective. J Neurochem 60:1978-2009.

Nagakawa O, Ogasawara M, Fujii H, Murakami K, Murata J, Fuse H, and Saiki I (1998). Effect of prostatic neuropeptides on invasion and migration of $\mathrm{PC}-3$ prostate cancer cells. Cancer Lett 1:27-33.

Nyeki O, Rill A, Schon I, Orosz A, Schrett J, Bartha L, and Nagy J (1998). Synthesis of peptide and pseudopeptide amides inhibiting the proliferation of small cell and epithelial types of lung carcinoma cells. J Pept Sci 8:486-495.

Ogasawara M, Murata J, Ayukawa K, and Saimi I (1997). Differential effect of intestinal neuropeptides on invasion and migration of colon carcinoma cells in vitro. Cancer Lett $1: 111-116$

Palma C, Bigioni M, Irrissuto C, Nardelli F, Maggi CA, and Manzini S (2000). Anti-tumour activity of tachykinin NK1 receptor antagonists on human glioma U373 MG xenograft. $\mathrm{Br}$ J Cancer 82:480-487.

Palma C, Nardelli F, and Manzini S (1999a). Correlation between binding characteristics and functional antagonism in human glioma cells by tachykinin NK1 receptor antagonists. Eur J Pharmacol 374:435-443.

Palma C, Nardelli F, Manzini S, and Maggi CA (1999b). Substance $P$ activates responses correlated with tumour growth in human glioma cell lines bearing tachykinin NK1 receptors. Br J Cancer 2:236-243.

Porta M, Malats N, Jariod M, Grimalt JO, Rifa J, Carrato A, Guarner L, Salas A, Santiago-Silva M, Corominas JM, Andreu $M$, and Real FX (1999). Serum concentrations of organochlorine compounds and K-ras mutations in exocrine pancreatic cancer. Pankreas II Study Group. Lancet 354:2125-2129.

Pour PM, Egami H, and Takiyama Y (1991). Patterns of growth and metastasis of induced pancreatic cancer in relation to the prognosis and its clinical implications. Gastroenterology 100:529-536.

Quartara L and Maggi CA (1997). The tachykinin NK1 receptor. Part I: Ligands and mechanisms of cellular activation. Neuropeptides 31:537-563.

Reubi JC, Mazzucchelli L, Hennig I, and Laissue JA (1996). Local up-regulation of neuropeptide receptors in host blood vessels around human colorectal cancers. Gastroenterology 6:1719-1726.

Reubi JC, Mazzucchelli L, and Laissue JA (1994). Intestinal vessels express a high density of somatostatin receptors in human inflammatory bowel disease. Gastroenterology 106: 951-959.

Reubi JC, Zimmermann A, Jonas S, Waser B, Neuhaus P, Laderach U, and Wiedenmann B (1999). Regulatory peptide receptors in human hepatocellular carcinomas. Gut 5:766774 .

Roggo T, Friess H, and Weihe E (2002). Neuroimmune cross-talk: What can we learn from inflammatory disorders? In: Büchler MW, Friess H, UhI W, and Malfertheiner $\mathrm{P}$, editors. Chronic pancreatitis 2000: Novel concepts in biology and therapy. Berlin: Blackwell Science, 170-176. 
Scott DT, Lam FY, and Ferrell WR (1994). Acute joint inflammation: Mechanisms and mediators. Gen Pharmacol 25:1285-1296.

Shrikhande SV, Friess H, di Mola FF, Tempia-Caliera A, Conejo-Garcia JR, Zhu ZW, Zimmermann A, and Büchler MW (2001). NK-1 receptor gene expression is related to pain in chronic pancreatitis. Pain 91:209-217.

Sobin LH and Wittekind C (1997). TNM classification of malignant tumours, 5th ed. New York: John Wiley \& Sons, Inc..

Swinscow TDV, editor (1988). Statistics at square one. Plymouth: Latimer Trend \& Company Ltd.

Walsh DA, Salmon M, Mapp PI, Wharton J, Garrett N, Blake DR, and Polak JM (1993). Microvascular substance P binding to normal and inflamed rat and human synovium. J Pharmacol Exp Ther 267:951-960.

Wang L, Friess H, Zhu Z, Frigeri L, Zimmermann A, Korc M, Berberat PO, and Büchler MW (2000). Galectin-1 and galectin-3 in chronic pancreatitis. Lab Invest 8:1233-1241.

Winkler A, Papsdorf G, Odarjuk J, Siems WE, Fickel J, and Melzig MF (1995). Expression and characterization of the substance $P$ (NK1) receptor in the rat pituitary and AtT20 mouse pituitary tumor cells. Eur J Pharmacol 1:51-55.
Yamaguchi K, Chijiiwa K, Torato N, Kinoshita M, and Tanaka M (2000). Ki-ras codon 12 point and P53 mutations: A molecular examination of the main tumor, liver, portal vein, peripheral arterial blood and para-aortic lymph node in pancreatic cancer. Am J Gastroenterol 8:1939-1945.

Zhu ZW, Friess H, di Mola FF, Zimmermann A, Graber HU, Korc M, and Büchler MW (1999). Nerve growth factor expression correlates with perineural invasion and pain in human pancreatic cancer. J Clin Oncol 17:2419-2428.

Zhu ZW, Friess H, Wang L, Di Mola FF, Zimmermann A, and Büchler MW (2000a). Down-regulation of nerve growth factor in poorly differentiated and advanced human esophageal cancer. Anticancer Res 20:125-132.

Zhu Z, Kleeff J, Friess H, Wang L, Zimmermann A, Yarden Y, Büchler MW, and Korc M (2000b). Epiregulin is up-regulated in pancreatic cancer and stimulates pancreatic cancer cell growth. Biochem Biophys Res Commun 3:1019-1024. 